\title{
Kirzner e a tentativa de aproximação da Escola Austríaca com outras abordagens: evidências a partir de textos menos conhecidos *
}

\author{
Lucas Casonato ${ }^{* * * * * *}$ \\ Eduardo Angeli ${ }^{* * * *}$
}

\begin{abstract}
Resumo
O artigo apresenta o pensamento econômico de Israel Kirzner expresso nas resenhas de livros, comentários e respostas que ele escreveu ao longo da carreira. Propõe investigar e sistematizar as características do pensamento econômico do autor que emergem nesse material: sua relação com a praxeologia misesiana, outras perspectivas para a teoria de atividade empresarial e sua percepção de diferentes correntes econômicas. Justifica-se a escolha desse material pelo engajamento profissional de Kirzner, que procurou dialogar com outras escolas econômicas.
\end{abstract}

Palavras-chave: Israel Kirzner, 1930-, Pensamento econômico, Engajamento profissional.

\begin{abstract}
Kirzner's attempt to build bridges between the Austrian School and other approaches: evidence from lesser known works

The paper presents the economic thought of Israel Kirzner, expressed in book reviews, commentaries, and responses that he has written throughout his career. It proposes to investigate and systematize the characteristics of the author's economic thought that emerge in this material: his relationship with the Misesian praxeology, other perspectives of the theory of entrepreneurship, and his perception of different economic schools of thought. The material chosen is justified by the professional engagement of Kirzner, who sought to dialogue with other economic schools.
\end{abstract}

Keywords: Israel Kirzner, 1930-, Economic thought, Professional engagement.

JEL: B31. B25. B53.

\section{Introdução}

Israel Kirzner é um personagem central para a Escola Austríaca de Economia. Seus trabalhos contribuíram para a retomada de interesse e expansão teórica nessa corrente do pensamento econômico (Barbieri, 2001, p. 35). Vaughn (1994, p. 92-93) reconhece Kirzner como uma das três figuras que se destacaram no "Austrian revival" a partir de meados da década de 1970.

Ao longo de suas principais obras, Kirzner defendeu consistentemente a teoria Austríaca para o entendimento dos fenômenos econômicos, pautando-se nas contribuições do par Mises-Hayek (Kirzner, 2011 [1963]; 2013 [1973]; 1979; 1992b; 2000). Porém, muita ênfase foi dada, inclusive pelo próprio autor, à sua proposição da função empresarial no processo de mercado, sendo a atividade

${ }^{*}$ Artigo recebido em 7 de maio de 2019 e aprovado em 2 de julho de 2020. Os autores agradecem a Armando Dalla Costa, Fabio Barbieri, Felipe Almeida, Ramón Fernández e a dois pareceristas anônimos pelas valiosas críticas e sugestões, eximindo-os dos erros e omissões. O presente trabalho foi realizado com apoio da Coordenação de Aperfeiçoamento de Pessoal de Nível Superior (CAPES) Código de Financiamento 001.

** Professor de Economia da Pontifícia Universidade Católica do Paraná (PUCPR), Curitiba, PR, Brasil. E-mail: casonato.economia@gmail.com. ORCiD: https://orcid.org/0000-0003-1280-3049.

${ }^{* * *}$ Professor da Faculdade de Educação Superior do Paraná (FESPPR), Curitiba, PR, Brasil.

***** Professor do Departamento de Economia da Universidade Federal do Paraná (UFPR), Curitiba, SP, Brasil. E-mail: angeli@ufpr.br. ORCiD: https://orcid.org/0000-0001-6676-9267. 
empresarial o campo de estudo em que Kirzner é considerado uma das principais referências (Boettke; Sautet, 2009, p. xi). A ideia chegou a ser inserida pelo próprio autor na discussão de outras questões na economia, como os pré-requisitos para o desenvolvimento econômico e a justiça distributiva (Boettke; Rizzo, 1995, p. xiii). Para Douhan et al. (2007, p. 217-220) é possível relacionar a atividade empresarial de Kirzner a um leque de temas ainda maior, como a formulação de políticas econômicas, liberdade, justiça e crescimento econômico.

Este artigo investiga e sistematiza as características do pensamento econômico de Kirzner que emergem nos trabalhos escritos com base na revisão de algum material anterior. Esses textos são resenhas de livros, comentários e respostas a trabalhos de outros autores, trabalhos menos conhecidos de Kirzner, mas propícios à ilustração sobre o engajamento profissional do autor. De acordo com Caldwell, conforme mencionado por Boianovsky, Kirzner utiliza, na defesa da visão Austríaca, um estilo argumentativo que busca estabelecer comparações com outras correntes de pensamento. ${ }^{1}$

Subjacente à escolha de tais textos, está a hipótese de que Kirzner adota uma postura de engajamento com o restante da profissão, superando as barreiras existentes entre as diferentes correntes de pensamento econômico. Isso é percebido na disposição do autor em revisar, comentar e responder textos e autores das mais diversas correntes, não se restringindo ao Austrianismo ou ao mainstream. Essa é uma atitude defendida pelo próprio Kirzner, que acredita ser vantajosa a discussão teórica entre diferentes perspectivas para o progresso científico (Kirzner, 1989b, p. 235). Tal hipótese é compatível com a posição usualmente atribuída ao papel central que Kirzner exerceu no "Austrian revival", como o de uma espécie de expoente que propunha uma maior proximidade do Austrianismo com o mainstream (Vaughn, 1992, p. 260; 1994, p. 5)2.

Por sua importância para a teoria Austríaca, e em especial para a teoria da atividade empresarial, Kirzner teve suas obras escrutinadas em diversos trabalhos. Porém, é possível verificar que os que trataram da teoria do autor ${ }^{3}$, ou que o utilizaram para discutir temas adjacentes ${ }^{4}$, não tiveram como objetivo jogar luz sobre seu pensamento econômico a respeito de questões não relacionadas à teoria da atividade empresarial ou ao Austrianismo. Tal ausência deixou uma lacuna na literatura, acerca do pensamento econômico de Kirzner sobre temas diversos.

Suprir essa ausência torna-se relevante para a compreensão da contribuição teórica de um autor de tamanha importância, bem como da escola de pensamento que ele ajudou a recuperar, permitindo um entendimento melhor a respeito de ambos. Logo, justifica-se analisar esse conjunto selecionado dos trabalhos de Kirzner por três razões: (i) o autor viu-se incitado a escrever sobre temas que não compunham necessariamente sua agenda de pesquisa, pela necessidade de revisar, comentar

(1) Mauro Boianovsky, presidindo o comitê de nomeação ao "Distinguished Fellow Award" de 2018 da History of Economics Society, explica que Caldwell defendeu a designação de Kirzner ao prêmio por sua postura de utilizar a história do pensamento econômico para comparar outras abordagens econômicas a visão Austríaca. A carta está disponível em: https://historyofeconomics.org/wpcontent/uploads/2018/06/Kirzner_Distinguished-Fellow-1.pdf. Acesso em: 21 out. 2018.

(2) Para Douhan et al. (2007, p. 221) "Kirzner's most important contribution may be that he has made the Austrian School intelligible to other economics scholars".

(3) Por exemplo Lewin (2002); Sautet (2002); Jakee e Spong (2003); Douhan; Eliasson e Henrekson (2007), Boettke (2014) e Korsgaard; Berglund; Thrane e Blenker (2016).

(4) Como Barbieri (2001), Koppl (2002); Holcombe (2003); Boettke e Coyne (2003); Boettke e D’Amico (2010); Callahan (2010); Foss e Klein (2010); Horwitz (2010) e McCaffrey (2014). 
ou responder algum material prévio; (ii) parte dos trabalhos discutidos influenciou suas obras, já que constam nestas como referências, o que será apontado; (iii) esse material não é comumente utilizado nas pesquisas sobre o seu pensamento econômico ou sua teoria da atividade empresarial ${ }^{5}$.

Além dos materiais publicados por Kirzner após a listagem mais recente de sua obra ${ }^{6}$, existem outros textos do autor que não aparecem nessas listas, mas que serão utilizados neste ensaio. Ainda assim, por falta de acesso, nem todos os materiais de interesse listados na publicação mencionada puderam ser encontrados para utilização, e por isso estão ausentes da revisão bibliográfica realizada. Foram analisadas 36 resenhas, oito respostas e 11 comentários escritos pelo autor que puderam ser acessados. A escolha deles para exame segue o entendimento de que nesses materiais pouco explorados pela literatura o autor encontrou-se defronte à necessidade de lidar com temas que não compunham necessariamente sua própria preocupação teórica, e isso permite duas possibilidades: (i) entender que eles apareceram a Kirzner como oportunidade para o uso de sua abordagem comparativa entre a Escola Austríaca e outras correntes, discutindo temas diversos na forma com que estão imersos em seu pensamento econômico; (ii) explorar o ponto de vista do autor com relação a questões que não estiveram necessariamente relacionadas ao seu objeto de pesquisa, embora possam ter lhe servido de referência futura em outros trabalhos.

Propõe-se que a análise do material escolhido seja dividida por temas, a fim de apresentar os resultados da investigação realizada. Apesar da diversidade de assuntos encarados por Kirzner nos trabalhos selecionados, foi possível identificar alguns que aparecem recorrentemente, agrupados da seguinte maneira: (1) a relação do autor com a praxeologia misesiana; (2) outras perspectivas sobre sua teoria da ação empresarial não discutidas recorrentemente nas obras do autor sobre o tema; e (3) a percepção kirzneriana com relação a distintas correntes econômicas. Para cada um destes temas, o artigo dedica uma seção, seguidas pelas considerações finais.

\section{Relação com a praxeologia}

A primeira característica que emerge do pensamento econômico de Kirzner nesse conjunto analisado de suas obras é a relação do autor com a praxeologia misesiana. Em seu primeiro livro, Kirzner defendeu a praxeologia como estudo da ação humana (Kirzner, 2009 [1960], p. 185). Neste sentido, seria um campo mais geral que a própria ciência econômica, que seria apenas um dos seus ramos (Kirzner, 2009 [1960], p. 186). Assim, a visão praxeológica admitiria que a teoria econômica surge da observação de uma faceta particular da ação humana.

O tema ressurge no primeiro artigo conhecido de Kirzner, que inicia o "debate BeckerKirzner", episódio assim denominado por Boettke e Sautet (2009, p. xvii). Para estes, as respostas de Kirzner ilustram uma abordagem praxeológica na metodologia do autor pela forma como ele explica a racionalidade na economia. Tal debate envolveu quatro artigos, dois de Becker $(1962 ; 1963)$ e dois de Kirzner (1962; 1963), começando com a resposta de Kirzner a um artigo de Becker, seguido de uma réplica de Becker e uma tréplica de Kirzner (Boettke; Sautet, 2009, p. xvii).

(5) Vale notar que Boettke e Sautet, organizadores do "The Collected Works of Israel M. Kirzner", deram atenção especial a esses materiais. Além de incluir algumas resenhas e respostas escritas por Kirzner, também adicionaram alguns dos artigos que os motivaram, como se vê em Boettke e Sautet (2009; 2016; 2018).

(6) Boettke et al. (2002). 
De acordo com Kirzner (1962, p. 380), Becker (1962) teria proposto defender o uso da hipótese de racionalidade na teoria econômica tradicional, motivado pelas críticas que apontavam a dependência desse pressuposto para as conclusões teóricas. Como forma de defesa, Becker teria escolhido provar que os resultados dos teoremas econômicos seriam válidos mesmo suprimindo essa hipótese, objetivando mostrar que, mesmo nesse caso, a economia se comportaria como se os tomadores de decisão agissem racionalmente. Daí poderia concluir pela independência da teoria tradicional, e seus resultados, com relação à racionalidade assumida.

A defesa de Becker iniciaria com a afirmação de que a curva de demanda no mercado é negativamente inclinada independentemente da racionalidade dos agentes. Esse seria um resultado objetivo, considerando que toda a renda concentrada poderia adquirir quantidades cada vez menores conforme os preços fossem aumentando. Porém, argumenta Kirzner, Becker não explica a razão de uma inclinação negativa, já que, na falta de racionalidade, não se poderia afirmar nada sobre o comportamento dos preços, o que também invalidaria qualquer interação entre as curvas de demanda e oferta (Kirzner, 1962, p. 380-381).

Kirzner aponta que a teoria tradicional considera o preço de equilíbrio a partir da intersecção entre oferta e demanda por uma razão implícita. Quando os preços esperados pelos indivíduos são diferentes dos de equilíbrio, ocorre uma frustração nos planos dos agentes, levando à sua revisão até que o equilíbrio seja atingido (Kirzner, 1962, p. 381). Com isso, Kirzner busca esclarecer o papel do erro na frustração das expectativas: o erro seria o responsável por garantir que os participantes do mercado revisem os planos, permitindo a tendência ao equilíbrio. Como na ausência de racionalidade não há revisão de planos, perde-se a certeza da emergência de um preço de equilíbrio (Kirzner, 1962, p. 382). Assim, não há como remover a hipótese de racionalidade dos agentes na ciência econômica, uma vez que se admite como racional toda ação propositada em que os indivíduos agem deliberadamente para alcançar um fim previamente estabelecido - um ponto de vista praxeológico.

Becker respondeu a Kirzner buscando discutir que seu argumento permanecia verdadeiro apesar das críticas recebidas. Porém, segundo Kirzner, Becker teria interpretado a crítica como uma discussão sobre a estabilidade do equilíbrio, quando na verdade a discussão estaria centrada no movimento iniciado na situação fora das condições do equilíbrio. O cerne da discussão, para Kirzner, era a possibilidade de alcançar o equilíbrio por meio da revisão de planos dos agentes, com a necessidade intrínseca de alguma racionalidade por parte dos indivíduos (Kirzner, 1963, p. 84).

Becker teria usado em sua resposta o exemplo de mercado com um único produto, cujo preço, inicialmente acima do de equilíbrio, vai sendo reajustado para baixo, mesmo com formadores de preços irracionais. Para Kirzner, Becker falha em apresentar a motivação que leva os agentes à revisão de planos na ausência de racionalidade. Não encontrando explicação desse resultado com base na análise dos demandantes no modelo proposto, Kirzner sugere que Becker só pode ter em perspectiva os vendedores. Estes utilizariam estratégias diversas para vender os produtos acumulados do período anterior. Assim, abre-se a possibilidade de que Becker tenha assumido alguma racionalidade em seu modelo, que levaria esses vendedores a revisarem suas estratégias de venda (Kirzner, 1963, p. 8485). Uma racionalidade condizente com a praxeologia, da ação propositada.

O “debate Becker-Kirzner" ilustra como Kirzner (1962; 1963) utiliza a abordagem comparativa para defender um ponto de vista praxeológico. Uma vez que Becker havia tentado 
descartar a hipótese de racionalidade para mostrar a validade dos teoremas econômicos, Kirzner mostra como uma definição mais geral e subjetiva para a racionalidade é imprescindível para a ciência econômica. Assim, as duas versões divergem sobre o significado desse conceito. Com isso, Becker estaria em posição de excluir a racionalidade enquanto comportamento específico de maximização. Porém, não poderia ignorar a racionalidade como defendida por Kirzner, a partir da propensão humana à revisão dos meios para o alcance dos próprios fins, proposição que serve de base à praxeologia misesiana.

Kirzner também defenderá implicitamente a praxeologia se se admite que esta possa ser entendida como método de análise econômica a partir da ação humana. Tal defesa é feita na resenha do livro de Briefs (1960). A inclinação kirzneriana se volta à defesa do método da teoria pura, que acredita condizente com a teoria econômica, independendo das ferramentas matemáticas. Para Kirzner é suficiente conceber a intencionalidade na ação humana para a interpretação dos fenômenos sociais (Kirzner, 1963, p. 615).

Tal defesa será novamente encontrada em outro artigo de Kirzner na década de 1960. A motivação deste artigo é a publicação de um discurso de Buchanan (1964) sobre a função do economista. No texto, Buchanan teria defendido que os economistas mudassem seu foco de análise dos problemas de alocação para as discussões cataláticas, ou seja, sair das preocupações com a eficiência para entender os resultados da propensão humana à troca. Isso porque discutir a alocação só teria sentido na decisão individual, em que um agente isolado se depara com um problema a ser solucionado. Essa discussão não caberia na economia de mercado porque os seus resultados emergem das interações sociais de vários agentes decidindo isoladamente (Kirzner, 1965, p. 257).

Segundo Kirzner, Buchanan identifica a preocupação com a alocação na proposta do problema econômico colocado por Lionel Robbins, considerando meios escassos e fins alternativos. Porém, Buchanan teria falhado na percepção de que Robbins não propusera que a economia resolvesse o problema da alocação no mercado, seja para um indivíduo isolado ou para toda a sociedade. No entendimento kirzneriano, a economia pensada por Robbins seria o estudo de como os homens resolvem o problema econômico, para explicar os fenômenos resultantes desse processo. Então o núcleo da proposta robbinsiana seria caracterizado por uma posição metodológica, analisar "[...] a particular aspect of human activity", a partir do qual se extrairiam leis e teorias para o entendimento das regularidades observadas no mundo real. Deste modo, Buchanan estaria considerando um aspecto particular na proposta de Robbins, ignorando a ideia de "logic of choice" que complementa essa posição. Para Kirzner, isso implica a incapacidade de opor-se completamente à proposta robbinsiana. Tal objeção poderia ser feita colocando-se em perspectiva os planos individuais dos agentes, o que já teria sido realizado por economistas como Mises e Hayek, que teriam conclusões semelhantes à de Buchanan sobre a necessidade de mudar o foco da economia (Kirzner, 1965, p. 258-259).

Assim, Kirzner sustenta sua posição afirmando que existem duas visões concorrentes na economia sobre o conhecimento gerado na análise econômica. A primeira seria o grupo dominante, que admite a ciência econômica como uma ciência empírica, cujo desenvolvimento perpassa a análise das regularidades observadas nos fenômenos econômicos, levando aos avanços teóricos. Nesta vertente, a economia permite um conhecimento através dos mesmos métodos utilizados nas ciências 
físicas. Já a segunda visão seria defendida por um grupo menor, entendendo que a economia permite um conhecimento do mundo real a partir das "[...] logical implications of human purposefulness, under various possible sets of circumstances" (Kirzner, 1965, p. 260). Tal vertente acredita ser capaz de avançar com relação aos métodos existentes nas ciências físicas por permitir um conhecimento sobre questões não observáveis, ao considerar que há aspectos subjetivos a serem compreendidos na ação humana. Essa segunda forma é apresentada por Kirzner como a visão praxeológica, que entende como foco de análise da ciência econômica os planos individuais que os agentes estabelecem, considerando a alocação de recursos necessária para alcançar seus propósitos. Assim, essa proposta de concepção, originada nas ideias de Mises e Robbins, não seria passível das críticas feitas por Buchanan, ao mesmo tempo que manteria as vantagens na sua busca por substituir o foco da economia, da alocação para a catalática (Kirzner, 1965, p. 260).

Verifica-se neste artigo que Kirzner (1965) vale-se da abordagem comparativa para defender a praxeologia misesiana, ao reinterpretar a definição econômica de Robbins e associá-la à visão de Mises. Isso permite ao autor atingir dois objetivos, embora só o primeiro esteja declarado. Kirzner responde as críticas de Buchanan e defende o método praxeológico como forma de compreensão dos fenômenos sociais pela economia, avançando com relação ao que é observado empiricamente.

Outra oportunidade utilizada por Kirzner para a defesa da praxeologia foi na análise do livro de Shackle (1966). Na resenha, discute como Shackle considera que o ambiente de incerteza transforma a decisão humana. A inclusão dessa condição mudaria o processo de escolha na teoria econômica, do cálculo mecânico, determinado pelo conjunto de informações, para uma atividade imaginativa e criativa que não guarda relação com o passado (Kirzner, 1967, p. 209). Kirzner chama a atenção para o fato de o trabalho econômico de Shackle ser bastante carregado de psicologia, já que a decisão humana é interpretada a partir de fatores introspectivos. Porém, a resenha aponta que a posição adotada por Shackle não invalidaria a análise da pura "logic of choice", já que esta é, no plano da mente, como se o indivíduo se deparasse com opções que conhecesse com certeza. Para Kirzner, entretanto, o economista não precisa conhecer os fatores psicológicos que antecedem ou perpassam a escolha para o sucesso da análise. Basta conhecer o propósito adotado pelo tomador da decisão (Kirzner, 1967, p. 210).

Desta forma, Kirzner (1967) utiliza a resenha do livro de Shackle para defender a praxeologia dividindo analiticamente a formação da decisão e a sua realização, para contrastar o seu resultado com o objetivo incialmente assumido pelo indivíduo. Assim, Kirzner acaba por limitar o grau de subjetividade a ser admitido no entendimento do processo decisório. Conquanto admita buscar maior compreensão do fenômeno por meio do subjetivismo, demonstra não ser necessário avançar ao ponto de conhecer as características mentais que atuam no processo decisório. Portanto, neste texto a abordagem comparativa serve a Kirzner como forma de mostrar a aderência entre a proposta de Shackle e a pura "502ogico f choice" decorrente da visão praxeológica da economia.

Na década de 1980 Kirzner (1982) retorna à defesa da praxeologia ao tratar tangencialmente do tema na discussão da adoção de hipóteses nos modelos econômicos, durante a resenha do livro de Lepage (1978). Para Kirzner, Lepage procurou relacionar o desenvolvimento das pesquisas em teoria econômica na América com os problemas sociais e de políticas públicas que promoveram disputas ideológicas na época. Para Lepage, um grupo teria se destacado no fornecimento das bases para a 
defesa da filosofia do livre mercado na economia, os "new economists", formados na grande maioria por membros da Universidade de Chicago e do Instituto Politécnico da Virgínia. Segundo Kirzner, Lepage considerou que tais pesquisadores demonstraram empiricamente a validade do homo economicus. Assim, para Lepage, seria somente com a contribuição desses profissionais que houvera a demonstração da validade científica do capitalismo, avançando por não dependerem da retórica ou da fé em sua sustentação. É essa última consideração que será contestada por Kirzner na resenha (Kirzner, 1982, p. 34-35).

Kirzner se descreve incomodado principalmente porque o autor teria relacionado o tratamento do capitalismo pelos "new economists" com o livro "Human Action" de Mises, ao comparar a racionalidade dos primeiros com a praxeologia do segundo. Com isso, Kirzner assume que a racionalidade considerada por Lepage dependeria de se considerar a ação como propositada. Porém, Kirzner afirma a incompatibilidade entre essas versões, porque na racionalidade utilizada pelos "new economists", também defendida por Lepage, depende-se de quais fins são almejados na ação, não sendo suficiente apenas a existência de objetivos predefinidos. Para Kirzner, esse é o grande motivo de crítica: o fato de uma defesa tão sólida do capitalismo, como a promovida pelos "new economists", ter como base uma argumentação tão frágil. Segundo Kirzner, Lepage estaria consciente de que tal defesa estaria sustentada em uma hipótese distante da realidade, mas que seria passível de aceitação em decorrência da capacidade preditiva advinda dela (Kirzner, 1982, p. 35).

Na resenha do livro de Lepage, Kirzner (1982) utiliza a abordagem comparativa para contrastar a diferença de significado entre o conceito de racionalidade para os "new economists" e o defendido por Mises. A definição da qual partem os primeiros seria dependente de fins préconcebidos da ação individual, porque sua racionalidade dependeria da eficiência da decisão para alcançar o objetivo assumido. Já no conceito misesiano, advindo da visão praxeológica da economia, a racionalidade só seria avaliada pela consistência entre fins e meios, tornando-a independente da eficiência no alcance do fim admitido.

Outro material em que Kirzner busca defender a praxeologia nesse período é a resenha do livro de Blaug (1980). Para Kirzner, Blaug teria feito uma análise equivocada do Austrianismo em razão de ter se pautado nos critérios científicos que acredita válidos, o monismo metodológico e o falseacionismo, levando-o à conclusão de que a Escola Austríaca seria dogmática e estrita. Kirzner busca inicialmente esclarecer o significado desses dois aspectos para Blaug. O monismo metodológico seria a negação de que haja um dualismo na metodologia, com a divisão entre os métodos adequados para as ciências naturais e as ciências sociais. O falseacionismo seria a base de validação da teoria científica, cuja aceitação depende de as previsões serem passíveis de testes empíricos (Kirzner, 1984, p. 5).

Kirzner, então, propõe ignorar as discussões pontuais no trabalho de Blaug para defender a praxeologia. Esse objetivo é realizado por meio da discussão de um teorema praxeológico no Austrianismo, que assevera a existência da tendência de os preços de um bem convergirem para um único preço quando o mercado é livre. Para Kirzner, embora essa seja a base para a Lei da Indiferença de Jevons, ela não passaria no critério falseacionista, por exemplo, pelas constantes mudanças verificadas no mundo real. Assim, tal Lei estaria empiricamente falseada, embora poucos economistas estejam dispostos a excluí-la da teoria econômica (Kirzner, 1984, p. 6). 
De acordo com Kirzner, a Escola Austríaca encontra relações lógicas e sistemáticas que são geradas pelas ações propositadas dos agentes. Então, a existência de fenômenos que por sua natureza não podem ser compreendidos nas posições metodológicas admitidas por Blaug deveriam colocar em perspectiva a validade dessa metodologia. Kirzner afirma que Blaug negou arbitrariamente a validade da posição Austríaca de teorizar com base na praxeologia. Tal arbitrariedade seria decorrente de Blaug discutir fenômenos regulares não verificáveis através de uma metodologia que depende de observações empíricas (Kirzner, 1984, p. 6-7).

Com isso, a comparação promovida nessa resenha permite a Kirzner (1984) mostrar o maior poder de investigação da praxeologia com relação ao falseacionismo, por dar conta tanto dos fatores observáveis como não observáveis empiricamente. Neste sentido, o primeiro método é colocado como mais geral que o segundo. Tal se dá com o avanço do subjetivismo, que aumentaria, na perspectiva kirzneriana, a capacidade do economista compreender as ações que os agentes tomam e os fenômenos econômicos que daí emergem.

Já nos anos 2000, na resenha do livro de Bauer (1957), Kirzner defenderá a praxeologia com a admissão de que a ação propositada é a característica central do agente econômico. Segundo Kirzner, Bauer teria iniciado suas discussões sobre o papel das atitudes humanas no potencial de desenvolvimento econômico dos países em desenvolvimento, pela crença existente de que contextos específicos nesses lugares inviabilizariam o uso da teoria econômica básica. Tal ideia assumiria que as instituições e atitudes humanas nesses países seriam diferentes, atuando de maneira distinta sobre os incentivos individuais (Kirzner, 2005, p. 465). Em razão disso, modelos econômicos estariam sendo criados e defendidos com base nas relações empíricas observadas nos países em desenvolvimento, deixando de lado a teoria econômica básica como a ferramenta de oferta e demanda. Bauer, na contramão dessas propostas, teria defendido o uso dos instrumentos convencionais por acreditar que, independentemente do contexto, “[...] human beings share a basically 'economic' logic [...]”. Essa atitude seria o auto interesse pelo próprio bem-estar (Kirzner, 2005, p. 466).

Kirzner mostra que as críticas enfrentadas por Bauer nas discussões do desenvolvimento econômico são as mesmas que geralmente se direcionam à economia tradicional. Com isso, aponta a distância entre o comportamento humano e aquele esperado do homo economicus. O núcleo das críticas decorre da argumentação de que os indivíduos não estariam buscando sempre maximizar seus ganhos pecuniários. Assim, Kirzner busca defender que ao considerar a ação dos agentes como propositada, serão irrelevantes as características que lhe forem atribuídas, como o egoísmo ou o auto interesse. Para ele, basta que se considere a "[...] human propensity to manipulate scarce means consistently toward the achievement of adopted goals". Portanto, levando em conta a existência de propósito nas decisões individuais, os resultados do processo de mercado continuariam válidos sendo os indivíduos tanto egoístas quanto altruístas. Isso porque tais agentes manteriam sua propensão empresarial para a identificação das possibilidades de lucro (Kirzner, 2005, p. 467). Logo, Bauer estaria certo em sua afirmação de que as diferentes atitudes nos países em desenvolvimento não invalidariam a teoria econômica simples, independentemente das diferenças contextuais (Kirzner, 2005, p. 468).

Ao final da resenha, Kirzner faz uma sistematização da ação propositada, caracterizada em três pontos: (i) escolha de objetivos; (ii) consistência na busca por 504ogico -los, mesmo que se 
modifiquem os meios no processo; (iii) estado de alerta para as novas possibilidades de alcançar os fins objetivados. A partir disso, Kirzner conclui que o propósito da ação humana não é uma atitude particular, da qual dependeria o desenvolvimento econômico. Antes, a ação propositada seria uma característica de todos os seres humanos, não sendo específica do homo economicus, mas comum a todo homo sapiens (Kirzner, 2005, p. 469).

Nesta resenha, Kirzner (2005) apresenta sua visão de que a validade dos preceitos teóricos sobre o comportamento humano propositado prevalece em diferentes ambientes e contextos. Sua perspectiva é apresentada em comparação com a posição defendida por Bauer, com quem concorda sobre a universalidade da teoria econômica básica. Dessa concordância se extrai a generalidade da hipótese sobre o comportamento humano, qual seja, a de que o propósito na ação individual não seja uma característica do agente no mercado, mas um atributo que é comum a toda espécie humana, tal qual afirmado na praxeologia misesiana.

Se os materiais propícios à abordagem comparativa entre as décadas de 1960 e os anos 2000 mostram Kirzner defendendo a praxeologia frente à teoria econômica tradicional, não é isso o que se encontra em um trabalho publicado por ele em 2010. Na resposta que Kirzner dirige a um artigo de Klein e Briggeman (2010), o autor se depara com a questão de priorizar a teoria ou o método misesiano. Para Kirzner (2010, p. 56-69), os autores fazem diversas críticas à sua própria teoria, sustentadas em um conjunto de proposições, tal como Kirzner ter admitido como inseparável a teoria misesiana do processo de mercado e a praxeologia.

Porém, nesta resposta, Kirzner afirma que tem tentado desde seus primeiros trabalhos mostrar como é possível separar "Mises's understanding of economic processes from the epistemological framework in which Mises himself developed that understanding" (Kirzner, 2010, p. 58). Kirzner defende ser possível entender e admitir o processo de mercado elaborado por Mises independentemente de se aceitar a praxeologia. Esclarece que essa percepção o levou, bem como a outros seguidores do Austrianismo moderno, a entender como Hayek, embora não aceitando a praxeologia misesiana, chegara na mesma concepção de Mises sobre um mercado competitivo dinâmico. Nessa discussão, Kirzner aproveita para esclarecer que a economia Austríaca moderna não segue Mises e Hayek na praxeologia, antes, o faz no interesse sobre a natureza do processo de mercado (Kirzner, 2010, p. 58-59).

Neste último trabalho em que Kirzner (2010) utilizou a abordagem comparativa para tratar da praxeologia, esclareceu seu pensamento com relação ao expresso por seus críticos quanto à importância do método praxeológico no Austrianismo. Sua defesa é de que a praxeologia, enquanto metodologia de pesquisa, não é unânime para a Escola Austríaca, que é unida, antes, pela teoria do processo de mercado. Com isso, afirma pela possibilidade de separar a teoria misesiana de sua abordagem praxeológica.

Nos trabalhos anteriores verifica-se uma busca por elementos que corroborem a importância das assertivas praxeológicas frente à teoria econômica tradicional. Nesta resposta, entretanto, Kirzner (2010) está preterindo a praxeologia em prol da teoria do processo de mercado de Mises, tornando a última disponível mesmo para quem rejeite o método praxeológico, embora ele não tenha criticado este último. 
No conjunto de textos discutido nessa seção, a praxeologia misesiana é defendida por Kirzner por diferentes ângulos e a partir de diferentes temas. Ele a defende como baseada na hipótese mais básica de que toda ação humana é racional, porque deriva da escolha de meios para o alcance de fins anteriormente estabelecidos (Kirzner, 1962; 1963). Essa racionalidade independe das motivações que guiam essas decisões (Kirzner, 1967), ou de alguma natureza intrínseca ao comportamento humano (Kirzner, 2005). Racionalidade essa que é contrastável com aquela admitida na teoria econômica tradicional, porque na versão praxeológica existe uma independência com relação aos fins (Kirzner, 1982). Enquanto metodologia, a admissão kirzneriana da praxeologia segue o entendimento presente em seu primeiro livro (Kirzner, 2009 [1960]), de que permite maior grau de subjetividade na interpretação dos fenômenos econômicos, aumentando a capacidade de compreendê-los (Kirzner, 1963; 1965). O mérito da praxeologia é independer daquilo que é empiricamente observável ou concebido a partir da análise matemática (Kirzner, 1963; 1965; 1984).

O questionamento que surge, portanto, é a motivação por detrás da hierarquização entre dois temas no pensamento econômico kirzneriano, a praxeologia e a teoria do processo de mercado. Quando discutindo a teoria econômica tradicional, sua tentativa foi a utilização da sua abordagem comparativa para defender os princípios da praxeologia, baseados na ação humana propositada. Na defesa da teoria austríaca, entretanto, priorizou a tese do processo de mercado, separando a teoria do método misesiano para enfatizar a primeira, enquanto tema mais geral.

Não é objeto de investigação deste artigo apontar se a abordagem kirzneriana é ou não praxeológica, mas é possível afirmar algo acerca disso a partir dos trabalhos consultados. Kirzner utiliza a praxeologia como ferramenta de trabalho de maneira geral. Isso é percebido na incessante defesa da "506ogico f choice", sob a ótica da praxeologia para a análise econômica, bem como no entendimento da ação humana, sob a ótica da construção teórica.

\section{Outras perspectivas sobre a teoria kirzneriana da atividade empresarial}

A segunda característica que emerge do pensamento econômico de Kirzner nesse conjunto analisado de suas obras é o surgimento de outras perspectivas para a teoria da atividade empresarial, que não são comumente tratadas na defesa da função empresarial nas obas mais conhecidas do autor (e.g. Kirzner, 2013 [1973]; 2016 [1989]; 1997). Destacam-se temas como sua função social, seus prérequisitos institucionais, e a justificativa ética ${ }^{7}$.

A função social da atividade empresarial é tangenciada por Kirzner na resposta já mencionada que dirigiu a Ricketts no livro editado por Caldwell e Boehm (1992). Nessa revisão, Kirzner aponta que a função empresarial dá origem a uma tendência ao equilíbrio que não é apenas econômico, mas também social. No pensamento econômico kirzneriano as oportunidades de ganho surgem em um arcabouço institucional específico, e o seu aproveitamento gera uma tendência à coordenação social que é relativa às instituições em que ela ocorre (Kirzner, 1992a, p. 92-93). Ou seja, em Kirzner a

(7) A afirmativa de que Kirzner tratou em menor grau das questões éticas reconhece que ele dedicou um livro e alguns artigos à questão, como se vê em Boettke e Sautet (2016). Porém, tal assertiva leva em consideração que, conquanto os outros aspectos da teoria da atividade empresarial sejam usados recorrentemente em suas obras, a discussão ética fica confinada, grosso modo, apenas aos trabalhos dedicados e essa temática. 
eliminação das oportunidades de lucro dentro de uma estrutura institucional leva à coordenação social porque tende a eliminar as possibilidades de ganho econômico no arcabouço em que elas ocorrem.

O tema retorna de maneira mais elaborada em outro trabalho já mencionado, na resposta de Kirzner a Klein e Briggeman (2010). Ao valer-se da coordenação como referência analítica, Kirzner (2010) explica, é possível diferenciar os aspectos que são bons para a sociedade e aqueles que lhe são apenas economicamente bons. Ou seja, de um ponto de vista estritamente teórico, essa separação permitiria o estabelecimento de relações de causa e efeito puramente econômicas, conquanto possam ter resultados sociais indesejados (Kirzner, 2010, p. 71-72). Kirzner apontou como exagerada a crítica recebida de que teria defendido a função empresarial como uma atividade sempre promotora dos melhores resultados. Na crítica, haveria consideração da existência de casos como o das bolhas especulativas, em que não há a promoção de melhoria econômica, embora haja motivação empresarial dos agentes envolvidos. A defesa kirzneriana é de que, aos olhos de uma "coordenação concatenada", como se houvesse um observador onisciente zelando pela sociedade, os resultados obtidos por vias empresariais poderiam ser tomados como danosos. Porém, na perspectiva da "coordenação descentralizada" - em que cada indivíduo possui apenas uma parcela do conhecimento - a função empresarial será sempre coordenadora, porque promove o melhor interesse do indivíduo e, com isso, dissemina conhecimento sobre situações para as quais anteriormente havia ignorância (Kirzner, 2010, p. 80-81).

As condições institucionais para a realização da função empresarial também aparecem na resposta de Kirzner a Ricketts (1992). No pensamento econômico kirzneriano a avaliação de viabilidade das oportunidades depende da existência dos direitos de propriedade. Existindo, permitem o planejamento dos agentes, já que um indivíduo que ignore tal sistema incorrerá em crime. Logo, se um indivíduo percebe uma oportunidade de ganhos que exige a mudança do arcabouço institucional no qual está inserido, a mudança dessa estrutura é, para ele, uma oportunidade empresarial. Para Kirzner, quando se considera que um ganho possa ser almejado a partir da alteração no conjunto de regras existentes como uma atividade empresarial, daí surge uma perspectiva evolucionária para a economia a partir da ação empresarial. (Kirzner, 1992a, p. 91-92). Assim, os insights sobre a tendência ao equilíbrio econômico permitem compreender a característica evolutiva das mudanças institucionais (Kirzner, 1992a, p. 92-93).

Também da resposta de Kirzner a Ricketts (1992) se tem a discussão do caráter ético da função empresarial. De acordo com Kirzner, Ricketts teria tentado invalidar seu argumento, apontando que uma parte importante dos lucros recebidos pelos proprietários de recursos não caberia na definição de lucro empresarial. Isso porque tais ganhos configurariam uma renda robbinsiana proveniente da própria posse de capital. Então, os recursos ganhos no mundo real pelos proprietários de renda não seriam passíveis de justificação ética ou explicação teórica na perspectiva da proposta kirzneriana de lucro puro (Kirzner, 1992a, p. 94-95). Para Kirzner, essa interpretação é decorrente de não se separar analiticamente os lucros entre puros e não-puros, considerando todos os ganhos como uma só receita da atividade desenvolvida, recebida pela posse de algum recurso (Kirzner, 1992a, p. 95-96). Logo, Ricketts estaria desconsiderando o fato de que a ação está sendo realizada sob incerteza, o que torna parte dos resultados do capitalista, mesmo sendo ele proprietário de recursos, um empresário (Kirzner, 1992a, p. 96-97). 
E essa discussão do caráter ético volta a aparecer também na resposta a Klein e Briggeman (2010). A crítica dos autores teria apontado para o problema ético na coordenação pela atividade empresarial, já que nisso o agente estaria explorando a ignorância dos demais. Kirzner defende-se apontando que, uma vez aceito o sistema de propriedades privadas, é a função empresarial, enquanto parte da ação humana, que coordena os interesses individuais (Kirzner, 2010, p. 78).

Para ilustrar essa questão, Kirzner diferencia o mercado das instituições voluntárias, cuja separação é a motivação pelo lucro puro. Para Kirzner, no mercado emergem padrões de atividades e fenômenos, incluindo aí instituições - secundárias -, todos eles são originados pela motivação dos ganhos. Já as instituições voluntárias, como o sistema de propriedade privada, são tomadas como arranjos sociais admitidos por sua capacidade de reforçar expectativas ou compartilhar ideias, independentemente dos lucros que possam gerar. Assim, no pensamento kirzneriano esses arranjos voluntários não resultam da espontaneidade na coordenação comercial. Kirzner rejeita inclusive a associação entre a possibilidade de crimes lucrativos com sua defesa da teoria da atividade empresarial, já que em sua proposição há a necessidade de um sistema legal prévio, outra instituição voluntária (Kirzner, 2010, p. 79-80). Respeitar as instituições é uma forma de qualificação ética à função empresarial.

Em resumo, Kirzner utilizou essa parcela específica da sua obra para fazer alguns apontamentos importantes acerca da sua teoria da atividade empresarial, que não aparecem de maneira corrente em seus principais textos sobre o tema. Assim, emergem outras perspectivas para a função empresarial. Além da coordenação econômica, ela também permite uma tendência ao equilíbrio social com relação às instituições a que estão confinadas. Isso porque as mudanças institucionais também podem ser buscadas pelos empresários que veem nisso uma possibilidade de ganho, conferindo o caráter evolutivo das instituições (Kirzner, 1992a). A função empresarial pode ser observada de duas maneiras: (i) a partir da onisciência, em que ela é economicamente boa, mas com possibilidade de resultados sociais ruins; (ii) a partir do conhecimento disperso, em que ela é economicamente boa e socialmente desejável, por coordenar a sociedade com a disseminação de informações (Kirzner, 2010). A atividade empresarial exerce o papel de disseminar conhecimento inclusive sobre as brechas nos arranjos institucionais.

Da mesma forma, emergem outras questões acerca dos elementos da sua teoria. Os direitos de propriedade privada tornam-se relevantes para a função empresarial não só por garanti-la, mas por permitir seu planejamento (Kirzner, 1992a). E com a admissão desses direitos pode-se considerar como ética a exploração da ignorância no mercado por parte dos empresários, porque fazendo isso eles atenderão melhor aos interesses dos agentes econômicos (Kirzner, 2010).

\section{Entendimento acerca de outras escolas econômicas}

A terceira característica que emerge do pensamento econômico de Kirzner nesse conjunto analisado de suas obras é o seu entendimento acerca de outras abordagens econômicas que não a neoclássica, recorrentemente tratada por ele em outros textos. Em alguns momentos também emerge a proposta kirzneriana de como a função empresarial é necessária na abordagem Austríaca ou tem espaço na teoria de outras escolas econômicas. 
Revisando o livro de Smith (1988), Kirzner aponta o material como uma contribuição para as mais diversas áreas das ciências sociais baseada no Austrianismo. A tese central do livro, segundo a resenha, é que a sociedade estaria priorizando preocupações de curto prazo e, com isso, permitindo problemas futuros. Smith teria sugerido resolver isso com reformas institucionais para incentivar o planejamento de longo prazo (Kirzner, 1989a). Nessa resenha Kirzner (1989a) utiliza a abordagem comparativa para ilustrar sua perspectiva acerca do Austrianismo com relação a Smith. Com base nisso dá ênfase a duas ideias que acredita inerentes à Escola Austríaca, conciliação intertemporal das preferências e impossibilidade de superprodução.

Para Kirzner, Smith entende que a utilização da renda pelos indivíduos reflete suas preferências temporais. Porém, parece a Kirzner que Smith chega a aceitar a proibição do exercício dessas preferências por vias institucionais, o que não seria admissível do ponto de vista Austríaco. Isso refletiria uma falta de confiança no livre mercado, por não creditar a ele a conciliação entre interesses presentes e futuros. Embora o livro de Smith tome o Austrianismo como base, Kirzner afirma que falta nele a compreensão Austríaca sobre a alocação temporal. No pensamento econômico kirzneriano a alocação não tem relevância pela possibilidade de acumular riqueza ao longo do tempo, mas por atender a preferências presentes sobre o futuro (Kirzner, 1989a).

Outro ponto criticado por Kirzner é que Smith estaria admitindo a Lei de Say em sua proposta como parte do pensamento Austríaco, considerando que a oferta guia as possibilidades de demanda. Segundo Kirzner, o Austrianismo não admite essa interpretação, porque, ao contrário, percebe a demanda como condutora da oferta. Smith estaria sendo induzido ao erro pela admissão Austríaca do insight da impossibilidade de superprodução existente na Lei de Say, o que, para Kirzner, não implica necessariamente aceitar a totalidade dessa proposição mais geral (Kirzner, 1989a).

Um novo contraste entre a visão kirzneriana da Escola Austríaca com relação a outros autores surge na resenha do livro de O'Driscoll e Rizzo (1985). Um ponto importante levantado por Kirzner nessa resenha versa sobre a possibilidade da tendência ao equilíbrio na economia. Kirzner retoma sua visão de existência dessa tendência, embora o equilíbrio nunca seja alcançável. Com isso, afirma que o livro adotou a posição subjetivista radical, admitindo uma volatilidade tamanha para os dados econômicos básicos que torna disruptivas as decisões dos agentes. Isso implicaria a necessidade de ignorar a possibilidade de forças econômicas que promovam padrões no mercado, resultando na inexistência de uma tendência coordenadora na economia (Kirzner, 1994b, p. 39-30).

Kirzner destaca que os precursores do Austrianismo, Mises e Hayek, partiram de um entendimento de mercado dinâmico por seu caráter competitivo (Kirzner, 1994b, p. 40-41). E mesmo isso permitiria uma tendência ao equilíbrio econômico. Então, para Kirzner (1994b, p. 42-43), quando O’Driscoll e Rizzo partem da incerteza genuína, acabam por rejeitar as contribuições misesianas e hayekianas que defendem a possibilidade de uma tendência ao equilíbrio econômico. Um estado que não é tomado como real, mas como ponto de referência teórico para a análise econômica.

Kirzner concede sobre a relevância de diferenciar aspectos típicos e únicos no futuro, proposta por O’Driscoll e Rizzo. Afirma que é possível concordar que muito da ação empresarial é uma tentativa de antecipação dos resultados dos eventos típicos, mais do que dos eventos únicos. Porém, para Kirzner, os autores não teriam mostrado os elementos de que dependeria o padrão de coordenação que eles propõem, por negarem o papel coordenador da função empresarial. Assim, 
haveria uma lacuna na explicação do fenômeno econômico na obra dos autores. Teria ficado em aberto explicar a motivação que os levou a negar a posição que Kirzner considera convencional na teoria Austríaca, a da atividade empresarial, se ela poderia cumprir esse papel (Kirzner, 1994b, p. 4243).

A reflexão que emerge da abordagem comparativa de Kirzner (1994b) nessa resenha versa sobre a base do Austrianismo na perspectiva kirzneriana, a junção das ideias de Mises e Hayek sobre o processo de mercado. Desta maneira, pode-se argumentar que em Kirzner a adoção de uma posição que se afaste daquilo que fora defendido por esses autores, como o abandono da tendência ao equilíbrio, seria o mesmo que afastar-se do Austrianismo.

Novo posicionamento contrário a uma nova definição de Escola Austríaca por parte de Kirzner é encontrado quando ele revisa o livro de Cordato (1992). Kirzner reconhece o mérito do livro em prover uma consistente crítica à teoria convencional do bem-estar, bem como pela conceituação acurada da eficiência catalática (Kirzner, 1993, p. 143).

Segundo Kirzner, Cordato define a cataláxia como a ordem social que emerge no mercado quando os indivíduos agem propositadamente. Sua eficiência é julgada pela capacidade institucional de garantir a propriedade privada e disseminar corretamente as informações. Com base nisso, a preocupação de Cordato teria se voltado para a avaliação do ambiente institucional, que no seu julgamento deve facilitar a ação propositada (Kirzner, 1993, p. 145). O problema surge, para Kirzner, quando Cordato deixa subentendida a possibilidade de usar políticas para o alcance de maior eficiência. No pensamento econômico kirzneriano isso representa uma mudança: da avaliação das condições institucionais em que ocorre o processo de mercado para a avaliação dos resultados do próprio mercado (Kirzner, 1993, p. 146-147).

De acordo com Kirzner, o critério de eficiência catalática de Cordato é uma excelente ferramenta de análise, passível de ser inserida na perspectiva Austríaca se ficar limitada às questões das condições institucionais. Mas, na forma como utilizada por Cordato, para Kirzner, corre-se o risco de extrapolar esses limites (Kirzner, 1993, p. 147).

Nessa resenha, Kirzner (1993) vale-se da abordagem comparativa para distinguir entre o critério de eficiência adotado por Cordato e aquele que ele próprio defende. O critério de eficiência catalática de Cordato seria baseado no nível de descoordenação, enquanto para Kirzner ele deveria basear-se na frustração/interrupção dos planos. Embora Cortado também tenha admitido esse aspecto, teria feito isso para afirmar que a frustração de planos tem efeitos descoordenadores. Já Kirzner admite a inconsistência sistêmica de planos entre os agentes como fator coordenador da economia. Por isso Cordato teria encarado o desapontamento de planos como ineficiente, enquanto Kirzner aponta-o como o promotor da eficiência catalática (Kirzner, 1993, p. 148-149).

Por fim, Kirzner também se colocará contrário à proposta de visão semi-Austríaca na resenha do livro de Reisman (1999), que teria proposto uma visão Austro-clássica para defender o capitalismo. As críticas kirznerianas focam na ideia de retomar posições abandonadas durante a revolução marginalista por já terem sido descartadas por Menger (Kirzner, 1999, p. 81).

Kirzner aponta que a busca por integrar ideias Austríacas e clássicas já estava presente na tese de doutorado de Reisman, que fora concluída em 1963 sob orientação de Mises na New York 
University. Segundo Kirzner, embora Mises tenha aprovado o trabalho, não concordou com a ideia central, conquanto Reisman acreditasse ter tirado esse insight da própria teoria misesiana (Kirzner, 1999, p. 82). A proposta Austro-clássica, em resumo, tentaria juntar uma visão objetiva das magnitudes econômicas com as ideias subjetivas do Austrianismo para compreender a economia. Adicionalmente, o material serviria de defesa do capitalismo contra as ideias marxistas e as teorias influenciadas pelo marxismo durante o século XX (Kirzner, 1999, p. 84).

Para Kirzner, Reisman se afasta da definição subjetiva da riqueza, dada em termos de preferências dos consumidores potenciais, para considerá-la em termos objetivos da promoção do bem-estar. Isso leva a um entendimento, no pensamento kirzneriano, de que a política pública deva ser orientada pela ciência econômica para a geração dessa riqueza, e não para a satisfação das necessidades manifestadas pelos indivíduos (Kirzner, 1999, p. 85). Conquanto Reisman tenha reconhecido afastar-se das abordagens econômicas pós-revolução marginalista, Austríaca e neoclássica, acreditaria integrar Austríacos e clássicos através das contribuições de Mises e Hayek (Kirzner, 1999, p. 85-86).

Kirzner ilustra por meio de alguns pontos centrais do Austrianismo que Reisman estaria ignorando as propostas de definição da economia de Robbins e Mises. Esses pontos são: (i) a explicação da compatibilidade dos planos entre múltiplos agentes que formam expectativas e tomam suas decisões individualmente; (ii) o entendimento de como os indivíduos são bem-sucedidos na antecipação das decisões dos demais, bem como no descobrimento e usufruto das oportunidades de lucro que o mercado apresenta; (iii) o esclarecimento para o processo de equilíbrio da economia, por meio do "[...] mutual learning and discovery [...]" (Kirzner, 1999, p. 86-87); (iv) a identificação dos lucros como resultado das ações empresariais; e (v) a percepção da precedência do consumo sobre a produção (Kirzner, 1999, p. 88-89).

Com essa última revisão sobre uma proposta de utilização do Austrianismo para uma nova proposição teórica, Kirzner (1999) utiliza sua abordagem comparativa para mostrar os elementos que acredita centrais na teoria Austríaca. Isso atende ao que parece ser o objetivo kirzneriano: mostrar como Reisman, embora acreditando aproximar-se da Escola Austríaca na utilização de algumas de suas ideias, está se afastando dela por minimizar aspectos que Kirzner admite como fundamentais. Adicionalmente, conquanto a ênfase dada em Mises e Hayek, surge a preocupação em manter a fidelidade às contribuições mengerianas, pela aversão ao resgate de ideias contemporâneas a Menger que ele já teria descartado.

Kirzner também expressou seu pensamento econômico acerca da abordagem marxista para a economia. Isso aparece inicialmente na resenha do livro de Ioannides (1992), que teria proposto uma crítica às novas abordagens Austríacas valendo-se de uma perspectiva marxista para o sistema de mercado. De acordo com Kirzner, apesar das divergências entre as duas correntes, o livro é de interesse dos economistas Austríacos por três razões: (i) os desenvolvimentos no Austrianismo para contrapor-se à ortodoxia neoclássica servem de base para a crítica a essas novas abordagens socialistas; (ii) o material contém uma cuidadosa revisão dos desdobramentos das teorias Austríacas que partiram das contribuições de Mises e Hayek; (iii) para conhecimento das críticas marxistas à Escola Austríaca. Apesar dessa importância, Kirzner admite que a resenha é breve pelas críticas 
providas pelo material serem injustas, ou então incompreensíveis para um não-marxista (Kirzner, 1994a, p. 44-45).

Kirzner nota que ao longo do livro é recorrente a crítica Austríaca à intervenção do governo pelo desconhecimento do resultado do fenômeno econômico. Porém, esse não seria o único motivo, já que Ioannides também estaria tomando a incerteza do resultado para além da imprevisibilidade, utilizando a contribuição de Lachmann para apontar a total indeterminação dos acontecimentos. Isso ocorre mesmo com o reconhecimento de que essa versão não é a "[...] dominant position among modern Austrian (since both Mises and Hayek emphatically recognized powerful stabilizing tendencies within markets) [...]". Então, a posição de Ioannindes sobre os Austríacos, para Kirzner, não recairia sobre uma característica essencial da escola como afirmado no livro (Kirzner, 1994a, p. 45).

Uma outra característica recorrente que Kirzner julga injusta seria a negligência da perspectiva dinâmica na proposta Austríaca, com a ideia defendida por Ioannides de que é possível prever os resultados de mercado sobre a distribuição de propriedade. Segundo Kirzner, essa posição é justificada pela posição marxista apresentada por Ioannides de que há uma dinâmica objetiva no uso do capital, excluindo o entendimento subjetivo das decisões econômicas. Para Kirzner, essa visão é derivada de uma interpretação equivocada do papel do capital no mercado, como se ele reproduzisse de maneira determinista a própria sociedade (Kirzner, 1994a, p. 45-46).

Essa resenha do livro de Ioannides é utilizada por Kirzner (1994a) para comparar suas ideias com relação à incerteza e à dinâmica econômica. Sobre a incerteza, mostra que ela não pode ser admitida como colocada por Lachmann, já que não seria a versão radical a adotada no arcabouço Austríaco principal que é derivado do par Mises-Hayek. Quanto à dinâmica econômica, Kirzner mostra como uma noção subjetiva acerca do capital e seu uso levam a um entendimento diferente quanto aos resultados econômicos, quando comparado à posição por ele identificada como marxista de encarar o capital e sua reprodução de maneira objetiva.

Também há um tratamento kirzneriano acerca da abordagem marxista na resposta a Burczak (2002) sobre a proposta da ética dos "finders-keepers" utilizada por Kirzner em sua defesa da justiça capitalista. Burczak estaria criticando o capitalismo pela falta de acesso a crédito dos agentes econômicos que não possuam capital prévio, comprometendo a capacidade desses indivíduos de realizar um lucro percebido no mercado por não ser possível aproveitá-lo. Logo, isso tornaria as oportunidades de lucro aproveitadas ilegítimas, já que apenas uma parte da sociedade pode disputar por elas, porque a parcela de indivíduos descapitalizada se encontraria incapaz de concorrer. Kirzner defende-se afirmando que sua proposta da ação empresarial independe da posse de recursos, uma vez que só depende da descoberta (Kirzner, 2002, p. 93-94).

Kirzner utiliza da abordagem comparativa para esclarecer acerca de seu entendimento sobre a decisão empresarial de utilização do capital, onde explicita seu pensamento acerca da abordagem marxista para o mesmo tema. Segundo Kirzner, o paradigma marxista para o lucro, tal qual o clássico, toma-o como um retorno do capital empregado na produção, e por isso essas abordagens permitiriam uma crítica à justiça distributiva no capitalismo (Kirzner, 2002, p. 94). Isso porque o capital se reproduziria de maneira cumulativa, favorecendo seus proprietários de maneira indefinida. Kirzner (2002, p. 94), entretanto, aponta que o erro nessa visão é negligenciar o caráter de descoberta na 
utilização do capital, uma vez que toda decisão, mesmo a de uso do capital, é feita em um ambiente de incerteza, para o qual não há garantia de retorno. É por isso que se reveste de importância a diferenciação feita por Kirzner entre a produção e a descoberta. Na decisão de produzir, objetivandose lucro, a atividade "[...] can no longer be seen as an act of pure discovery or "creation". Those who do not possess capital assets simply cannot "produce" profit [...]". (Kirzner, 2002, p. 94, negrito original).

Kirzner também tratou de abordagens keynesianas. Isso é feito de maneira breve e tangencial durante a revisão já mencionada do livro de Smith (1988). Nessa resenha Kirzner aponta dois erros que, em sua interpretação, Keynes teria cometido em sua proposição teórica. O primeiro seria apontar a possibilidade de insuficiência da demanda agregada na situação de equilíbrio econômico. O segundo seria sobre seu entendimento de poupança, porque em Keynes, na leitura de Kirzner, ela teria valor em si mesma enquanto objeto de decisão (Kirzner, 1989a). No pensamento econômico kirzneriano isso tem relevância na medida em que: (i) aponta o equilíbrio como estado de repouso na economia, em que todos os planos estão compatibilizados sem possibilidade percebida de melhora; e (ii) pela crença de Kirzner (1989a) de que a poupança só tem sentido quando entendida como decisão de consumir mais no futuro em relação à possibilidade presente de consumo.

Outra oportunidade em que Kirzner discute brevemente o keynesianismo é na resenha do livro de Skousen (1990). Kirzner entende que o livro busca criticar duas abordagens teóricas: (i) a crença keynesiana de que as forças de mercado não promovem a tendência ao pleno emprego; (ii) a crença de Clark-Knight sobre a possibilidade de ignorar a estrutura temporal do estoque de capital com uma análise atemporal da economia. No entendimento kirzneriano, Skousen teria tido sucesso em refutar a segunda abordagem, mas não a primeira, por falta de base teórica para tanto. Kirzner aponta que a base necessária para tanto seria considerar o dinamismo do processo de mercado que identifica de maneira empresarial os recursos ociosos para sua melhor alocação (Kirzner, 1991, p. 1762).

Então, nessa resenha Kirzner (1991) defende que a crítica à abordagem keynesiana perpassa a consideração da função empresarial no mercado. Com isso, mostra que a propensão à busca por ganhos dos agentes promove o movimento de alocação de recursos para a melhor utilização percebida. Essa dinâmica, de identificação e realocação, permite no pensamento econômico kirzneriano uma tendência ao pleno emprego dos recursos. Logo, em Kirzner, o pleno emprego sem ociosidade seria condizente com a situação de equilíbrio na economia.

Com base nesse material é possível distinguir duas características acerca no pensamento econômico kirzneriano. Em primeiro lugar emerge sua forma de interpretar diferentes abordagens econômicas, o Austrianismo, o marxismo e o keynesianismo. Em segundo, a preocupação em mostrar como a consideração da função empresarial em cada uma dessas correntes econômicas leva o resultado teórico para próximo do seu entendimento.

Para a primeira característica, da interpretação das diferentes escolas econômicas, é possível notar que Kirzner recusa admitir para o Austrianismo as propostas de políticas públicas que privem a liberdade individual, seja para a alocação temporal dos recursos (Kirzner 1989a), seja para buscar maior eficiência do mercado (Kirzner, 1993). Tais políticas devem permitir a satisfação das necessidades que os indivíduos manifestam (Kirzner, 1999), porque o livre mercado sozinho é capaz 
de manter a liberdade individual e coordenar ao longo do tempo os desejos dos agentes (Kirzner, 1989a). É a descoordenação dos planos que gera os incentivos à própria coordenação do mercado por meio da atividade empresarial (Kirzner, 1993).

Sobre o Austrianismo, Kirzner ainda destaca a necessidade de manter fidelidade às contribuições de Mises e Hayek. Porque ambos apontaram que o caráter empresarial gera o dinamismo do mercado, e embora isso promova a agitação nas condições econômicas, é justamente o que permite a tendência ao seu equilíbrio (Kirzner, 1994b). Mas não só Mises e Hayek devem ser levados em conta no pensamento econômico kirzneriano, como também prevalece uma fidelidade às ideias de Menger. Kirzner considera que algumas contribuições pré-1870 não seriam conciliáveis com o pensamento Austríaco porque já teriam sido descartadas nos trabalhos mengerianos (Kirzner, 1999).

Acerca do marxismo, Kirzner considera que ele admite a reprodução econômica de maneira determinística, com base na distribuição inicial dos recursos. Assim, a utilização de capital permitiria um resultado de acumulação que privilegiaria aqueles que já possuem posses prévias (Kirzner, 1994a; 2002). Já o entendimento kirzneriano acerca do keynesianismo dá destaque às ideias de: (i) insuficiência da demanda agregada no equilíbrio econômico (Kirzner, 1989a), por ociosidade dos recursos (Kirzner, 1991), e; (ii) a ideia de que poupar seja uma decisão econômica com fim em si mesma (Kirzner, 1989a).

A segunda característica, sobre como a função empresarial encaixa-se nessas diferentes abordagens econômicas, aproxima o resultado teórico de cada escola ao entendimento kirzneriano do processo de mercado. A partir das diferentes interpretações sugeridas para o Austrianismo, é possível ver como a função empresarial sozinha é capaz de adequar a alocação de recursos ao longo do tempo (Kirzner, 1989a), coordenar o mercado atuando sobre a incompatibilidade dos planos dos agentes econômicos (Kirzner 1993), e gerar riqueza independentemente de políticas voltadas para esse fim (Kirzner, 1999).

Quando tratando de abordagens marxistas, mostra como o processo de capital pode ser compreendido por meio do caráter subjetivo da tomada de decisão que ocorre em meio à incerteza. Essa perspectiva torna possível a percepção de que não há reprodução automática da riqueza no capitalismo, de modo que a distribuição inicial dos recursos não pode, sozinha, explicar o resultado futuro do mercado. Na perspectiva kirzneriana deve ser incluída a função empresarial para compreensão do processo de descoberta em cada resultado, que pode ser falível ao frustrar expectativas, não havendo ganhos garantidos (Kirzner, 1994a; 2002).

Por fim, discutindo a teoria keynesiana à luz da função empresarial, Kirzner defende que não há possibilidade de insuficiência da demanda agregada porque a propensão individual aos ganhos promoveria a alocação dos recursos econômicos ociosos (Kirzner, 1989a, 1991). Da mesma forma, a poupança não pode ser vista como uma decisão empresarial em si mesma, mas como um ato de buscar maior provimento de recursos no futuro com relação ao que é possível no presente (Kirzner, 1989a). 
Kirzner e a tentativa de aproximação da Escola Austríaca com outras abordagens: evidências a partir de textos menos conhecidos

\section{Conclusão}

A pesquisa de textos pouco conhecidos de Kirzner realizada neste artigo evidencia que o insight de Caldwell, mencionado na introdução deste artigo, de que aquele autor utiliza um estilo argumentativo baseado em comparações teóricas entre o Austrianismo e outras abordagens econômicas, é um guia relevante para a compreensão dos seus escritos econômicos. Isso ilustra o engajamento profissional de Kirzner, a tentativa de não se isolar do restante da profissão na discussão de diversos temas, tentado sempre aproximar a visão Austríaca daquilo que está sendo discutido por economistas não identificados com o paradigma misesiano-hayekiano. Com base nisso, constatou-se três temas que são recorrentes nessa parcela menos conhecida das obras kirznerianas: sua relação com a praxeologia, aspectos sociais da função empresarial, e o pensamento de Kirzner sobre outras escolas econômicas.

Em sua relação com a praxeologia é possível observar que Kirzner a defende de diferentes formas. Pode ser vista no pensamento kirzneriano auxiliando a análise econômica, aumentando a compreensão do fenômeno econômico pelo maior grau de subjetivismo, ou como ferramenta de construção teórica, baseada na racionalidade da ação humana. E constatou-se que Kirzner a utiliza de ambas as maneiras. Verificou-se também uma hierarquia entre a praxeologia e a teoria do processo de mercado, em que a segunda é preferida, quando Kirzner tem que apontar qual delas é mais relevante para a Escola Austríaca.

Embora tenha tratado da teoria da atividade empresarial em diversas obras, nos textos analisado existem contribuições a que Kirzner deu menor atenção, permitindo novas perspectivas sobre sua principal contribuição. Foram destacadas as funções sociais, éticas e institucionais da ação empresarial no pensamento kirzneriano, bem como o papel empresarial de dispersão do conhecimento acerca das possibilidades existentes no arcabouço institucional que rege o mercado.

Por fim, foram discutidas as interpretações de Kirzner acerca de novas abordagens sugeridas para o Austrianismo, bem como para o marxismo e o keynesianismo. Foi mostrado como o pensamento kirzneriano inclina-se à fidelidade a Menger, Mises e Hayek na discussão das ideias Austríacas, que ele torna dependente da teoria empresarial do processo de mercado. Ao tratar de abordagens marxistas, Kirzner posicionou tais visões econômicas como centradas no objetivismo e determinismo das relações econômicas, mostrando como ignoram o papel especulativo e subjetivo das decisões individuais. Sobre Keynes, conquanto reconheça o mérito em privilegiar o papel da demanda com relação a oferta, Kirzner mostra seu descontentamento quanto ao tratamento do desequilíbrio e da poupança. Para todas as três abordagens o pensamento econômico kirzneriano é capaz de apresentar uma versão empresarial do processo de mercado, que faria suas conclusões teóricas convergirem para aquela defendida por Kirzner.

\section{Referências bibliográficas}

BARBIERI, Fábio. O processo de mercado na Escola Austríaca Moderna. 2001. 188p. Dissertação (Mestrado)-Departamento de Economia, Faculdade de Economia, Administração e Contabilidade, Universidade de São Paulo, São Paulo, 2001. 
Lucas Casonato, Eduardo Angeli

BOETTKE, Peter J. Entrepreneurship, and the entrepreneurial market process: Israel M. Kirzner and the two levels of analysis in spontaneous order studies. The Review of Austrian Economics, v. 27, n. 3, p. 233-247, 2014.

BOETTKE, Peter J.; COYNE, Christopher J. Entrepreneurship and development: cause or consequence? In: KOPPL, Roger; BIRNER, Jack; KLITGAARD-KURRILD, Peter (Ed.). Advances in Austrian Economics. Emerald Group Publishing Limited, 2003. v. 6, p. 67-87.

BOETTKE, Peter J.; D’AMICO, Daniel J. Corridors, Coordination, and the entrepreneurial theory of the market process. Journal of Private Enterprise, v. 25, n. 2, p. 87-96, 2010.

BOETTKE, Peter J.; RIZZO, Mario J. Preface. In: BOETTKE, P. J.; KIRZNER, I. M.; RIZZO, M. J. (Ed.). Advances in Austrian economics. Jai Press, 1995. v. 2B, p. xiii-xv.

BOETTKE, Peter J.; SAUTET, Frédéric E. Introduction to the Liberty Fund edition. In: BOETTKE, P. J.; SAUTET, F. E. (Ed.). The collected works of Israel M. Kirzner: the economic point of view. Indianapolis: Liberty Fund, 2009. v. 1, p. xi-xix.

BOETTKE, Peter J.; SAUTET, Frédéric E. Introduction to the Liberty Fund edition. In: BOETTKE, P. J.; SAUTET, F. E. (Ed.). The collected works of Israel M. Kirzner: discovery, capitalism, and distributive justice. Indianapolis: Liberty Fund, 2016. v. 6, p. ix-xiv.

BOETTKE, Peter J.; SAUTET, Frédéric E. Introduction to the Liberty Fund edition. In: BOETTKE, P. J.; SAUTET, F. E. (Ed.). The collected works of Israel M. Kirzner: the essence of entrepreneurship and the nature and significance of market process. Indianapolis: Liberty Fund, 2018. v. 8, p. ix-xiv.

CALLAHAN, Gene. A comment on Klein/Briggeman and Kirzner. Journal of Private Enterprise, v. 25 , n. 2 , p. $105-115,2010$.

DOUHAN, Robin; ELIASSON, Gunnar; HENREKSON, Magnus. Israel M. Kirzner: an outstanding Austrian contributor to the economics of entrepreneurship. Small Business Economics, v. 29, n. 1-2, p. 213-223, 2007.

FOSS, Nicolai J.; KLEIN, Peter G. Alertness, Action, and the antecedents of entrepreneurship. Journal of Private Enterprise, v. 25, n. 2, p. 145-164, 2010.

HISTORY OF ECONOCMIS SOCIETY. Distinguished fellow award. 2018. Disponível em: https://historyofeconomics.org/wp-content/uploads/2018/06/Kirzner_Distinguished-Fellow-1.pdf.

Acesso em: 21 out. 2018.

HOLCOMBE, Randall G. The origins of entrepreneurial opportunities. The Review of Austrian Economics, v. 16, n. 1, p. 25-43, 2003.

HORWITZ, Steven. Kirznerian entrepreneurship as a Misesian solution to a Hayekian problem. Journal of Private Enterprise, v. 25, n. 2, p. 97-103, 2010.

JAKEE, Keith; SPONG, Heath. Praxeology, entrepreneurship and the market process: a review of Kirzner's contribution. Journal of the History of Economic Thought, v. 25, n. 4, p. 461-486, 2003.

KIRZNER, Israel M. Rational action and economic theory. Journal of Political Economy, v. 70, n. 4, p. 380-385, 1962. 
Kirzner e a tentativa de aproximação da Escola Austríaca com outras abordagens: evidências a partir de textos menos conhecidos

KIRZNER, Israel M. [Resenha do livro Three views of method in economics, por Henry W. Briefs (1960)]. Journal of Political Economy, v. 71, n. 6, p. 614-615, 1963.

KIRZNER, Israel M. What economists do. Southern Economic Journal, v. 31, n. 3, p. 257-261, 1965.

KIRZNER, Israel M. [Resenha do livro The nature of economic thought: selected papers, 1955-64, por G. L. S. Shackle (1966)]. The Journal of Business, v. 40, n. 2, p. 209-210, 1967.

KIRZNER, Israel M. Perception, opportunity, and profit: studies in the theory of entrepreneurship. Chicago: The University of Chicago Press, 1979.

KIRZNER, Israel M. Enter the new economists. [Resenha do livro Tomorrow, capitalism: the economics of economic freedom por Henri Lepage (1982)]. Inquiry, p. 34-35, 1982.

KIRZNER, Israel M. [Resenha do livro The methodology of economics, or how economists explain por Mark Blaug (1980)]. Austrian Economics Newsletter, v. 5, n. 1, 1984.

KIRZNER, Israel M. [Resenha do livro Time and public policy por T. Alexader Smith (1988)]. The Freeman, 1989a. Disponível em: https://fee.org/articles/book-review-time-and-public-policy-by-talexander-smith/. Acesso em: 10 abr. 2018.

KIRZNER, Israel M. The use of labels in doctrinal history: comment on Baird. Cato Journal, v. 9, n. 1, p. 231-237, 1989b.

KIRZNER, Israel M. [Resenha do livro The structure of production por Mark Skousen (1990)]. Journal of Economic Literature, v. 29, n. 4, p. 1761-1763, 1991.

KIRZNER, Israel M. Commentary: entrepreneurship, uncertainty and Austrian economics. In: CALDWELL, B. J.; BOEHM, S. Austrian economics: tensions and new directions. New York: Springer Science+Business Media, 1992a. p. 85-102.

KIRZNER, Israel M. The meaning of market process: essays in the development of modern Austrian economics. London: Routledge, 1992b.

KIRZNER, Israel M. [Resenha do livro Welfare economics and externalities in an open-ended universe: a modern Austrian perspective por Roy E. Cordato (1992)]. Cato Journal, v. 13, n. 1, p. 143-149, 1993.

KIRZNER, Israel M. [Resenha do livro The market, competition and democracy: a critique of neoAustrian economics por Stavros Ioannides (1992)]. The Freeman, 1994a. p. 44-46.

KIRZNER, Israel M. On The economics of time and ignorance. In: BOETTKE, P. J.; PRYCHITKO, D. L. (Ed.). The market process: essays in contemporary Austrian economics. Brookfield: Edward Elgar, 1994b. p. 38-44.

KIRZNER, Israel M. How markets work: disequilibrium, entrepreneurship and discovery. London: The Institute of Economic Affairs, 1997.

KIRZNER, Israel M. Report on a treatise. The Review of Austrian Economics, v. 12, n. 1, p. 81-94, 1999.

KIRZNER, Israel M. The driving force of the market. London: Routledge, 2000. 
Lucas Casonato, Eduardo Angeli

KIRZNER, Israel M. Comment on “A Critique of Kirzner's Finders-Keepers Defense of Profit”. The Review of Austrian Economics, v. 16, n. 1, p. 91-94, 2002.

KIRZNER, Israel M. Human attitudes and economic growth. Cato Journal, v. 25, n. 3, p. 465-469, 2005.

KIRZNER, Israel M. (1960). The Economic Point of View. In: BOETTKE, P. J.; SAUTET, F. E. (Ed.). The collected works of Israel M. Kirzner: the economic point of view. Indianapolis: Liberty Fund, 2009. v. 1, p. 1-189.

KIRZNER, Israel M. The meaning of "economic goodness": critical comments on Klein and Briggeman. The Journal of Private Enterprise, v. 25, n. 2, p. 55-85, 2010.

KIRZNER, Israel M. (1963). Market theory and the price system. In: BOETTKE, P. J.; SAUTET, F. E. (Ed.). The collected works of Israel M. Kirzner: market theory and the price system. Indianapolis: Liberty Fund, 2011. v. 3, p. 1-352.

KIRZNER, Israel M. (1973). Competition and entrepreneurship. In: BOETTKE, P. J.; SAUTET, F. E. (Ed.). The collected works of Israel M. Kirzner: competition and entrepreneurship. Indianapolis: Liberty Fund, 2013. v. 4, p. xv-200.

KIRZNER, Israel M. (1989). Discovery, capitalism and distributive justice. In: BOETTKE, P. J.; SAUTET, F. E. (Ed.). The collected works of Israel M. Kirzner: discovery, capitalism, and distributive justice, Indianapolis: Liberty Fund, 2016. v. 6, p. 1-169.

KOPPL, Roger. What is alertness? Journal des Économistes et des Études Humaines, v. 12, n. 1, p. 3-13, 2002.

KORSGAARD, Steffen; BERGLUND, Henrik; THRANE, Claus; BLENKER, Per. A tale of two Kirzners: time, uncertainty, and the "nature" of opportunities. Entrepreneurship Theory and Practice, v. 40, n. 4, p. 867-889, 2016.

LEWIN, Peter. Entrepreneurship and the defense of capitalism: an examination of the work of Israel Kirzner. Journal des Économistes et des Études Humaines, v. 12, n. 2, p. 203-212, 2002.

MCCAFFREY, Matthew. On the theory of entrepreneurial incentives and alertness. Entrepreneurship Theory and Practice, v. 38, n. 4, p. 891-911, 2014.

SAUTET, Frédéric E. Kirznerian Economics: Some Policy Implications and Issues. Journal des Economistes et des Etudes Humaines, v. 12, n. 1, p. 131-151, 2002.

VAUGHN, Karen I. The problem of order in Austrian economics: Kirzner vs. Lachmann. Review of Political Economy, v. 4, n. 3, p. 251-274, 1992.

VAUGHN, Karen I. Austrian Economics in America: the Migration of a tradition. Cambridge: Cambridge University Press, 1994. 